\title{
Noções de BioÉtica e do Direito da BIOMEdicina na EXPERIÊNCIA Francesa
}

\author{
NOTIONS OF BIOETHICS AND OF THE BIOMEDICAL LAW IN FRANCE
}

Eric Mondielli(*)

\section{RESUMO}

Depois de identificar os contornos do conceito de bioética, foram identificados e colocados em perspectiva os fatores que explicam o seu aparecimento. Em uma segunda etapa, analisaram-se as expressões "direito da biomedicina" e "direito da bioética", para distingui-las dos conceitos relacionados. Discutiu-se, também, se a bioética pode ser entendida como uma ciência, antes de identificar as especificidades do direito da bioética e discutir as lógicas envolvidas, que devem ser conciliadas nos debates sobre bioética. Finalmente, pareceu essencial insistir no princípio da salvaguarda da dignidade humana, como o princípio matriz da bioética e do direito da biomedicina, estando ele no coração de todos os debates e questões de bioética.

\section{Palavras-chave}

Bioética; Dignidade Humana; Direito da Biomedicina; Direito Médico; Proteção da Pessoa Humana.

\section{ABSTRACT}

After identifying the contours of the concept of bioethics, we identified and put into perspective the factors that explain its emergence. In a second

$\left(^{*}\right)$ Professor de Direito Público e diretor científico do Master 2 de Direito Internacional Europeu dos Direitos Fundamentais da Universidade de Nantes (ensino à distância); diretor-adjunto do Centro de Estudos e Pesquisas de Direito Europeu da Saúde de Nantes; integrante do Laboratório "Direito e mudança social" da Faculdade de Direito de Nantes. Especialista em Direito Internacional Europeu. E-Mail: <eric.mondielli@univ-nantes.fr>. Recebido em 10.5.10. Aprovado em 31.05.10 
step, we analyzed the terms "biomedicine law" and "bioethics law", to distinguish them from related concepts. It has been also argued, if bioethics can be understood as a science, before identifying the specificity of bioethics law, and discussing the different logic involved and that must be reconciled in discussions on bioethics. Finally, it seemed essential to insist on the principle of safeguarding human dignity, as the matrix principle of bioethics and biomedicine law, this principle being at the heart of all debates and issues of bioethics.

\section{Keywords}

Bioethics; Biomedical Law; Human Dignity; Medical Law; Protection of Human Being.

A bioética é um conceito particularmente difícil de se apreender, tais as incertitudes de seus contornos. Há quem se interrogue mesmo sobre sua existência. Ao longo do tempo, o termo "bioética" veio se juntar aos de ética, moral e deontologia. Frequentemente, usa-se ao lado do termo "bioética" a expressão "biomedicina". O médico, profissional da saúde, o biológo, o jurista ou o filósofo, cada um tem um olhar particular sobre o conceito. No final, todos esses elementos contribuem para uma certa confusão entre os cidadãos.

A bioética não é, necessariamente, uma disciplina universitária. Ela surge, como nos lembra o filósofo do direito Stéphane Bauzon, como um estudo interdisciplinar de questões éticas colocadas pela medicina e pelas ciências da vida. Para o autor de La personne biojuridique, o direito não pode definir a bioética lato sensu, mas contribui para lhe dar uma definição. Bauzon considera que "a bioética é um questionamento sobre a vida humana" e que "o direito pode lhe dar um elemento de resposta"(1).

Na sociedade pós-moderna, a bioética tornou-se uma preocupação mundial para diferentes autoridades (científicas, religiosas e espirituais, governamentais, legais, organizações internacionais etc.). Questão pública e democrática, ela chama a sociedade a fazer escolhas. Enfim, não há uma bioética, mas diferentes concepções da bioética (sem mencionarmos as abordagens norte-americana, latina, francesa....(2). Por definição, a bioética é plural, considerando tratar-se de um espaço de divergências de ideias.

$O$ nascimento da bioética está relacionado aos progressos fulgurantes das ciências médicas dos séculos XX e XXI. As novas possibilidades das

(1) BAUZON S. La personne biojuridique. Paris: PUF, Paris, 2006. p. 11. (Coll. Quadrige).

(2) Para uma ilustração desta diversidade, ver AZOUX-BACRIE L., (dir.), Bioéthique, bioéthiques, Bruxelles, Nemessis, Bruylant, 2003. 
ciências médicas, se trazem perspectivas de cura ou de atenuação dos sofrimentos humanos inesperados, até agora, podem, igualmente, provocar novos perigos de dominação, manipulação, seleção e subordinação.

A bioética obedece a vontade política de não deixar "a ciência sem consciência" para retomar uma fórmula célebre do escritor francês do século XIX, François Rabelais. Assim, este artigo, após ter descrito os contornos da noção de bioética, identificará os numerosos fatores que permitem explicar seu surgimento (I). Em um segundo momento, nos deteremos nas expressões "direito da biomedicina" e "direito da bioética" com o objetivo de distingui-las das diversas noções próximas (II). Investigaremos, igualmente, se a bioética pode ser compreendida como uma ciência (III) e, em seguida, identificaremos as especificidades do direito da bioética e as lógicas envolvidas e que devem ser conciliadas no debate sobre a bioética (IV). Enfim, para finalizar, parece indispensável nos determos sobre o princípio da salvaguarda da dignididade da pessoa humana, enquanto princípio matricial da bioética e do direito da biomedicina $(\mathrm{V})$, estando no centro de todos os debates e questionamentos sobre a bioética.

\section{A NOÇÃO DA BIOÉTICA E OS FATORES QUE EXPLICAM SEU SURGIMENTO}

Com o objetivo de apreender a noção de bioética, é fundamental voltarmos às origens do termo. Retorno este que permitirá uma melhor compreensão das diferenças entre as abordagens anglo-saxônica e francesa, após o que será conveniente colocar em perspectiva os principais fatores que explicam o surgimento da bioética.

\section{A noção de bioética}

O que pode se entender por "bioética"?

A utilização do termo é relativamente recente e sua origem é americana. A palavra aparece, pela primeira vez em 1970, no artigo do oncologista americano, Van Rensselaer Potter, intitulado Bioethics, the science of surviva/(3) e retorna em publicação de 1971, do mesmo autor, Bioethics: bridge to the future $^{(4)}$. Potter, constatando o desenvolvimento extraordinário do conhecimento científico, em particular da Biologia, e a falta de reflexão sobre a utilização

(3) VAN RENSSELAER POTTER. Bioethics, the science of survival. Perspectives in Biology and Medecine, n. 14, p. 127-153, 1970.

(4) VAN RENSSELAER POTTER. Bioethics: bridge to the future, Englewoods Cliffs. New Jersey: Prentice-Hall, 1971. 205 p. 
desse saber, desejava o advento de uma nova ciência - uma ciência da sobrevivência - com base na aliança do saber biológico ("bio") e dos valores humanos (ética).

O campo da bioética, para o pai da expressão, deveria englobar todas as dimensões que concorrem para a sobrevivência da espécie humana e do planeta (controle de população, paz, pobreza, ecologia, a vida animal, o bem-estar do homem etc.). Depois, como destaca Guy Durand(5) em seu Introduction générale à la bioéthique, a maioria dos autores limitou a palavra "bioética" às questões levantadas pelas ciências biológicas e suas aplicações medicinais.

Etimologicamente, a palavra "bioética" vem dos termos gregos "bios", a vida, e "ethos", o costume, que teve como um derivado, a partir do século XVIII, o termo "ethikê", significando aquilo que concerne aos costumes. Deve-se entender por "ética" (ethos) "a descoberta de uma boa maneira de ser ou a sabedoria da ação".

De uma maneira geral, pode-se considerar que, a partir do momento em que se penetra a esfera biológica ou médica, toda questão torna-se uma questão bioética. Segundo $N$. Lenoir e B. Mathieu, "a bioética remete às regras de conduta que uma sociedade se coloca a fim de fazer face às dificuldades ou aos dilemas nascidos dos avanços das ciências da vida"(6).

A definição da bioética proposta pelo grande filósofo Paul Ricœur, no prefácio do Código de Deontologia Médica, em 1996(7), parece particularmente esclarecedora, notadamente para o jurista; trata-se de "um conjunto constituído pela ética médica dirigida à prática clínica e pela ética médica orientada em direção à pesquisa, o que inclui a dimensão legal de onde pode-se delinear o conceito de biodireito".

A Convenção de Oviedo do Conselho da Europa da chamada "biomedicina" (4 de abril de 1997) traz uma definição de bioética em associação aos direitos humanos: "a proteção dos direitos do homem e da diginidade do ser humano, em relação às aplicações da biologia e da medicina"(8).

Para finalizar a questão da definição, é preciso, a fim de evitar confusões, sublinhar que os conceitos anglo-saxão e francês de bioética não são exatamente os mesmos. De fato, nos países de tradição anglo-saxônica, o termo faz referência ao conjunto de problemas morais levantados pela

(5) DURAND G. Introduction générale à la bioéthique. FIDES/Cerf, 1999. p. 565.

(6) LENOIR N.; MATHIEU B. Les normes internationales de la bioéthique. Paris: PUF, 1998. p. 7. (Que-sais-je?, n. 3356).

(7) CODE de déontologie médicale (Poche). Introduit et commenté par René (Ed.) Louis, préface de Paul Ricœur. Seuil, 1996. p. 205 (Coll. Points Essais).

(8) CONVENTION "BIOMÉDECINE" DU CONSEIL DE L'EUROPE. Disponível em: <http:// conventions.coe.int/Treaty/fr/Treaties/Html/164.htm>. 
proteção da vida humana. Por seu lado, na França, o conceito de bioética tem um significado mais estreito, uma vez que se refere somente aos problemas morais surgidos nas áreas da biologia e da medicina(9).

Na França, no campo jurídico, começou-se a utilizar o termo "bioética" não sem alguma hesitação. As primeiras leis que definiram a bioética foram de $1994^{(10)}$. De toda forma, é importante lembrar que nenhuma dessas leis continham o vocábulo "bioética" em seus títulos. Evidentemente, certas leis anteriores às de 1994 que tratam de questões como aborto (Lei Viel relativa à interrupção voluntária da gravidez de $\left.1974^{(11)}\right)$ ou a lei sobre experiências com seres humanos (conhecida como "Huriet-Sérusclat" de 20 de dezembro de 1988) têm uma dimensão bioética mesmo que, no momento de sua criação, não se utilizasse a palavra. A primeira lei na qual o legislador fez uso do termo bioética foi a Lei n. 2004-800 de 06 de agosto de 2004, relativa à "bioética"(12).

\section{Os fatores que explicam o surgimento da bioética}

Os fatores que explicam o surgimento da bioética nas sociedades foram claramente evidenciados pelo canadense G. Durand $^{(13)}$ e estão relacionados,

(9) Para se ter uma noção da abordagem francesa, pode-se consultar numerosos decretos do COMITÉ NATIONAL CONSULTATIF D'ÉTHIQUE POUR LES SCIENCES DE LA VIE ET DE LA SANTÉ. Disponível em: <http://www.ccne-ethique.fr/>.

(10) A pedra fundadora do direito da bioética seria colocada por três leis: Lei n. 94-653, de 29 de julho de 1994, que trata do respeito ao corpo humano; Lei n. 94-654, de 29 de julho de 1994, sobre doação e o uso de partes e produtos do corpo humano, a assistência médica, a proteção e ao diagnóstico pré-natal; Lei n. 94-548, de $1^{\circ}$ de julho de 1994, relativa ao tratamento de doadores nominados com o propósito de pesquisa na área da saúde e que modifica a Lei n. 78-17 de 06 de janeiro de 1978, relativa à informática, aos arquivos e à liberdade informatizada. Aos textos fundadores, é necessário acrescentar a Lei n. 94-630, de 25 de julho de 1994, que modifica o Livro II do Código de Saúde Pública, relativo à proteção de voluntários de pesquisas biomédicas. Em seguida, outros textos foram adotados como a Lei n. 2001-588, de 04 de julho de 2001, que trata da interrupção voluntária da gravidez e da contracepção (JO, 7 juill.) e a Lei n. 2002-303, de 04 de março de 2002, dos direitos dos doentes e da qualidade do sistema de saúde, conhecida como Lei "Kouchner".

(11) Sobre esta lei, ver a decisão do CONSEIL CONSTUTUTIONNEL. Décision n. 74-54 du 15 janvier 1975, Loi relative à l'interruption volontaire de la grossesse. Disponível em: <http://www.conseilconstitutionnel.fr/decision/1974/7454dc.htm>.

(12) Para uma mostra dos grandes textos legislativos franceses, os leitores podem consultar os sites que disponibilizam informações sobre a legislação francesa (o conjunto dos textos e os relatórios parlamentares estão catalogados e acessíveis): Dossier Législatif sur Legifrance. Disponível em: <http://www.legifrance.gouv.fr/>; <http://www.legifrance.gouv.fr/affichLoiPubliee.do;jsessionid =412A138D95732EC4945445F372DF2A1A.tpdjo09v_1 idDocument=JORFDOLE000017759387\& type=general>; Dossier Législatif de l'Assemblée Nationale. Disponível em: <http://www.assembleenationale.fr/12/dossiers/bioethique.aspv>; <http://www.assemblee-nationale.fr/13/dossiers/ eval_bioethique.asp>; <http://www.assemblee-nationale.fr/13/rap-off/i1325-tl.asp>; Dossier législatif du Sénat. Disponível em: <http://www.senat.fr/dossierleg/pjl01-189.html>. La Documentation Francaise. Sur la révision des lois de bioéthique en 2010 v. /Dossier d'actualité — La Documentation française: <http://www.ladocumentationfrancaise.fr/dossier_actualite/bioethique/ind(...)>.

(13) DURAND, G. op. cit., p. 28 et s. 
principalmente, aos desvios que a ciência biomédica conheceu no passado, ao desenvolvimento tecnocientífico, ao surgimento dos direitos individuais, à modificação da relação médico/paciente e, por fim, ao crescimento do que se chama, às vezes, de "pluralismo moral". Em resumo, a reflexão bioética está intimamente ligada à tomada de consciência das ameaças e pode ser analisada como uma reação aos perigos potenciais.

Passemos rapidamente aos fatores mencionados acima:

- Desvios da pesquisa biomédica: a divulgação mundial, graças ao processo de Nuremberg em 1947, das atrocidades cometidas pelo regime nazista nos campos de concentração, notadamente em matéria de experimentação com seres humanos, constituiu um momento importante para a reflexão bioética mundial. Para julgar os médicos acusados, foi adotado o Código de Nuremberg, que definiu dez princípios estabelecendo as condições nas quais as pesquisas com humanos seriam permitidas. Em seguida, em inúmeros países, notadamente ocidentais, diversos escândalos surgiram após experiências consideradas contrárias à ética, suscitando debates assim como uma tomada de consciência das pessoas sobre a vulnerabilidade de alguns indivíduos (prisioneiros, doentes mentais, pessoas consideradas antisociais entre outros).

- O desenvolvimento científico: de uma ciência "contemplativa" passamos, progressivamente, a uma "ciência ativa", pela sua associação com a tecnologia. Ciência e tecnologia são, desde então, indissociáveis. 0 progresso, principalmente em termos biomédicos, abre perspectivas sem precedentes em termos de melhoria, de manutenção e de prolongação da vida humana. Mas, ao mesmo tempo, estas novas perspectivas suscitam debates e polêmicas dentro da comunidade científica e, mais ainda, na sociedade. Estas controvérsias estão relacionadas aos medos do uso abusivo de novas técnicas científicas e aos riscos de seleção (espectro do eugenismo), por isso a necessidade premente de controle e reflexão. Citaremos, por exemplo, os avanços relacionados ao transplante de órgãos que trazem inúmeras questões sobre as condições de seleção de doadores vivos ou mortos; as perspectivas abertas pela genética que despertam, igualmente, uma série de questionamentos sobre a elaboração de testes de seleção genética e seus diversos usos; as técnicas de terapia gênica etc.

- O surgimento dos direitos individuais: se a Declaração Universal dos Direitos do Homem, da Assembleia Geral das Nações Unidas, de 10 de dezembro de 1948, afirmou a proteção da liberdade e da dignidade do indivíduo (o mesmo que o Código de Nuremberg), o texto inicial é, originariamente, estranho às questões éticas trazidas pela ciência e pela técnica em razão do contexto no qual ele foi elaborado. A ideia dominante da Declaração é, essencialmente, a de proteger o indivíduo contra os abusos do poder político. A ciência e a técnica não constituem, por elas mesmas, um perigo, uma vez que elas são muito mais percebidas como permissoras, "a 
luta contra o obscurantismo, a alienação e o dogmatismo: elas liberam e asseguram o bem-estar do indivíduo" (Hottois) ${ }^{(14)}$. A partir dos anos 60, na América, como na Europa, homens e mulheres se conscientizaram dos perigos do progresso científico e da necessidade de questionamento. Foi nesse período, como destaca corretamente G. Durand, que "a Declaração Universal dos Direitos do Homem viu seu papel modificado pelo advento de toda sorte de tecnologias". Particularmente, na Europa francofona "a filosofia dos direitos do homem (tornou-se) sempre uma fonte de inspiração múltipla para uma parte importante da reflexão bioética"(15). Ao mesmo tempo, assiste-se a um aumento da força das reivindações dos direitos individuais, do direito à autodeterminação. Este valor da autodeterminação pode ser visto, particularmente, em um texto emblemático da Associação Médica Mundial $(A M M)^{(16)}$ de 1981, a saber, a Declaração dos Direitos dos Doentes. Progressivamente, tanto na América como na Europa, diversas leis em benefício dos pacientes foram adotadas.

- A modificação da relação médico/paciente: a relação tradicionalmente caracterizada por uma certa proximidade entre o médico e seu paciente tem uma tendência a desaparecer pelo advento de uma nova medicina, mais técnica, mais especializada e apoiada sobre estruturas hospitalares e clínicas bastante específicas. A pessoa do paciente é negligenciada e enfrenta a lógica fria e impessoal da administração da saúde. A relação médica tende a se "desumanizar". No final, esta situação, progressivamente, nutriu um sentimento de desconfiança com relação ao corpo médico.

- O crescimento do "pluralismo moral": definido por David J. Roy como a "ruptura do consenso social, jurídico e religioso tradicional em relação aos valores morais"(17). A partir dos anos 60 , os valores e princípios sofreram um colapso em razão da contestação da autoridade (social, legal, religiosa, profissional). "Nenhum indivíduo ou grupo poderia mais determinar de maneira autoritária o que era bem ou mal" e, ao mesmo tempo, diversas morais e sistemas de valores se afirmaram em nossas sociedades. Assim, "o desenvolvimento do pluralismo social e moral" e a insatisfação ligada à "incapacidade das morais tradicionais (notadamente religiosa) de responderem às novas questões", no campo da biomedicina, criaram a necessidade de uma nova abordagem ética.

- A reflexão bioética inspirada pelo medo de certos perigos (heurística do medo): a reflexão bioética, enquanto desejo de combinar o avanço das

(14) HOTTOIS, G. Qu'est-ce que la bioéthique? Paris: Vrin, 2004.

(15) DURAND, G. op. cit.

(16) WORLD MEDICAL ASSOCIATION. Disponível em: <http://www.wma.net/en/10home/index.html>.

(17) J. ROY D., WILLIAMS J. R, M. DICKENS; BAUDOUIN J-L. La bioéthique: ses fondements et ses controverses. Montréal: Editions du Renouveau Pédagogique, 1995. p. 12; ouvrage cité par DURAND, G. op. cit., p. 43. 
ciências da vida e da medicina, foi construída em resposta à percepção dos perigos potenciais ${ }^{(18)}$, assim a origem do termo "bioética" e a evocação dos fatores de seu surgimento como demonstramos. Ela apresenta um pensamento pluridisciplinar, moral e ético sobre as implicações das ciências da vida sobre a sociedade, segundo definição proposta por Noëlle Lenoir ${ }^{(19)}$. A bioética que pretende regular o progresso científico conhece prolongamentos jurídicos. $O$ direito, de fato, foi mobilizado para interditar ou legitimar certas práticas científicas ou médicas. O filósofo Hans Jonas, em sua célebre obra Le principe responsabilité. Une éthique pour la civilisation technologique ${ }^{(20)}$, analisa a bioética como uma reação à inquietude suscitada pelo progresso da biologia e da genética. Jonas, apresentando a genética como uma nova ameaça, destaca que "o Prometeu (quer dizer, o homem) definitivamente 'desacorrentado' - a quem a ciência confere forças, até então, jamais conhecidas - reclama uma ética que, por entraves voluntários, impeça o poder do homem de se tornar uma maldição para si mesmo".

\section{DIREITO DA BIOMEDICINA, DIREITO DA BIOÉTICA E CONCEITOS PRÓXIMOS}

Biomedicina e bioética: deve-se fazer uma distinção entre as noções de bioética e de biomedicina?

De fato, algumas pessoas usam os termos "bioética" e "biomedicina" indiferentemente; para outros, eles não são conceitos idênticos, embora sejam intimamente ligados. Esta constatação merece atenção, para que possamos seguir adiante e nos posicionar em favor da afirmação de que os termos são distintos. Este posicionamento nos conduzirá, consequentemente, a considerar a esfera de ação do que se chama em direito sanitário "o direito da biomedicina". De toda forma, somos forçados a constatar que numerosos juristas, e notadamente os especialistas em liberdades públicas e direitos fundamentais, referem-se à noção de direito da bioética. Nos parece útil, por consequência, analisar os vários conceitos que estão em jogo quando se fala em direito da bioética, para, em seguida, nos atermos sobre a relação entre direito médico e direito da bioética.

\section{A biomedicina e a bioética: qual a diferença ?}

A biomedicina visa as práticas oferecidas pelo progresso das ciências da vida (biologia e medicina) aplicado ao homem. Como salientou Brigitte

(18) LENOIR N.; MATHIEU B. op. cit., p. 10.

(19) Id. Ibid.

(20) JONAS H., Le principe responsabilité. Une éthique pour la civilisation technologique, Paris, Le Cerf, 1990. Cité par LENOIR N. et MATHIEU B.,op. cit. 
Feuillet-Le Mintier(21), a composição "bio /medicina" traduz uma "vontade de unir a medicina com as técnicas oferecidas pela biologia". A existência da Convenção Europeia dos Direitos do Homem e da Biomedicina, de 04 de abril de 1997, adotada pelo Conselho da Europa, vem confirmar esta análise. O documento tem por objetivo assegurar "o respeito aos direitos e às liberdades fundamentais em relação às aplicações da biologia e da medicina" (Art. 1, al.1, Convention biomédecine) $)^{(22)}$.

A bioética é fundamentalmente uma reflexão pluridisciplinar e uma investigação sobre as respostas que o direito pode dar às questões éticas levantadas pelo progresso e pelas práticas da biologia e da medicina. É por esta razão que alguns observadores desse tema consideram - corretamente, a nosso ver - que é um pouco abusivo falar de "direito da bioética".

Em compensação, há sim um direito da biomedicina ou um direito biomédico, uma vez que as práticas médicas e biológicas foram objeto de um ordenamento jurídico. É, também, a razão pela qual teria sido mais apropriado para a lei de 06 de agosto de 2004, relativa à bioética, que o legislador adotasse uma outra denominação como a de "lei relativa à biomedicina". O legislador, no entanto, preferiu chamar de "lei relativa à bioética". Duas razões principais permitem explicar a escolha do legislador: em primeiro lugar, é evidente, a partir da exposição de motivos do projeto de lei (v. Doc. AN 200-2001, n. 3166, exposição de motivos, p. 4) que, para os criadores deste projeto, o termo bioética é mais comum do que outros (argumento mais deficiente, a nosso ver); uma segunda explicação é tratada por $J-R$ Binet(23), segundo o qual "a escolha do termo bioética corresponde mais ao que entende a opinião pública, o justiciável, o destinatário da norma". O autor destaca o quanto é essencial que a lei seja acessível. Este autor lembra, igualmente, que o legislador entendeu manter uma concepção mais ampla da bioética: "questionamentos éticos e sociais ligados às inovações médicas que implicam uma manipulação do ser vivo".

Assim compreendido, o termo se constitui em questões para quais a lei será uma resposta. A lei relativa à bioética de 06 de agosto de 2004 é, então, a resposta legislativa aos questionamentos éticos e sociais ligados às inovações médicas que implicam uma manipulação do ser vivo. Dessa maneira, não é impossível considerar que o legislador entendeu endossar, ao menos implicitamente, o método que consiste em fazer da reflexão bioética uma anticâmara da atividade parlamentar.

A apreciação e as referências do Comitê Consultivo de Ética Francês, na ocasião das discussões parlamentares, vêm claramente ao encontro dessa análise.

(21) In FEUILLET-LE MINTIER B. (Dir.). Normativité et biomédecine. Paris: Economica, 2003. (Coll. Etudes juridiques).

(22) CONVENTION "BIOMÉDECINE” DU CONSEIL DE L'EUROPE. Disponível em: < http:// conventions.coe.int/Treaty/fr/Treaties/Html/164.htm>.

(23) BINET, R-J. Le nouveau droit de la bioéthique, Lexis Nexis LITEC, 2005. (coll. Carré droit). p. 3 et s 


\section{A esfera de ação do direito da biomedicina}

A esfera de ação do direito da biomedicina, de acordo com a abordagem que da Convenção Europeia de Biomedicina (que trata do campo das práticas médicas), é ampla, uma vez que integra o "direito dos atos médicos não terapêuticos" assim como o "direito dos atos médicos terapêuticos".

O direito da biomedicina compreende: acesso a cuidados, o conjunto das intervenções dentro do campo sanitário, do genoma humano, da pesquisa científica, da seleção para transplantes de órgãos e tecidos de doadores vivos. Assim, o direito da biomedicina se distinguiria do direito médico que, de acordo com algumas abordagens ou interpretações restritivas, se estruturaria em torno de uma única "relação terapêutica" entre o médico e seu paciente. Para $B$. Feuillet-Le Mintier na composição "bio/medicina", o termo medicina é prepoderante. A autora considera que "o direito da biomedicina rege o uso das técnicas ou práticas que têm por objeto a conservação ou restabelecimento da saúde, saúde sendo compreendida em sua concepção moderna"(24).

\section{3. $O$ direito da bioética: as diferentes noções em jogo ${ }^{(25)}$}

Além do termo "direito da biomedicina", o que abrange a expressão "direito da bioética", frequentemente utilizada pelos especialistas em liberdades públicas e direitos fundamentais (sobre as críticas dirigidas à expressão "direito da bioética", ver acima - 1)?

Quando se fala de um "direito da bioética", diferentes noções estão em jogo, a saber, o direito, a deontologia e a ética. Um resumo rápido sobre estes conceitos se faz necessário.

O direito é um conjunto de regras de condutas exteriores, definidas pelo homem para reger as relações sociais, nas quais o respeito é assegurado, se necessário pela coerção pública.

O termo "deontologia" vem do grego deon-deontos, dever e logos, o discurso. A palavra foi, de fato, criada pelo filósofo utilitarista inglês Jeremy Bentham (1748-1832), no sentido geral de ciência da moral. O termo foi utilizado pela primeira vez, na língua francesa, em 1825, na tradução da obra de Bentham intitulada Essai sur la nomenclature et la classification des principales branches d'Art et Science. O dicionário Littré definiu o conceito como "a ciência dos deveres". A deontologia, em sua acepção atual, é o conjunto de regras de conduta que se impõe aos integrantes de uma profissão em seu exercício; assim, fala-se, por exemplo, de uma deontologia médica ou de uma deontologia

(24) FEUILLET-LE MINTIER B. (Dir.). op. cit.; notemos que é preciso distinguir, também, "direito da biomedicina" e "direito das biotecnologias" que regulamenta as técnicas de engenharia com organismos vivos. 
da enfermagem. Um código deontológico é "um conjunto textual estruturado e organizado reunindo os princípios enunciados pelas regras profissionais próprias ao exercício de uma profissão determinada"(26).

Enfim, a ética preconiza ao homem o respeito aos valores (um tipo de "moral laica"). Convém insistir sobre o papel fundamental do Comitê Nacional Consultivo de Ética para as Ciências da Vida (CCNE) ${ }^{(27)}$, que permitiu afirmar que "a bioética veio ao socorro do direito para identificar os novos contornos do direito de dispôr sobre o corpo e do direito à integridade física".

No entanto, qual a distinção que deve ser feita entre os conceitos de ética e moral? ${ }^{(28)}$

Moral e ética tem um sentido etimológico comum que significa "costumes", uma vez que "ética" vem do grego "ethos", e "moral" vem do latim "mores". Algumas vezes, utiliza-se de forma indiferente esses dois termos. De toda forma, é necessário se constatar que, em uma acepção contemporânea, eles não são idênticos. No que concerne à moral, distinguiremos as abordagens filosófica e atual.

Tradicionalmente, em matéria de filosofia moral, existem duas distinções principais: a ética normativa e a metaética. A vocação da primeira é "prescritiva", no sentido que ela tem por objeto dizer o que deve ser feito, o que é bom ou mal, justo ou injusto. A metaética é uma disciplina "descritiva", no sentido de que ela tem por objeto, em particular, propor a identificação de características específicas de julgamento moral em relação a outras formas de julgamento de ordem factual, estética etc.

Para o filosófo Ruwen Ogien ${ }^{(29)}$, há uma terceira disciplina subordinada a estas duas, a ética aplicada, que ele define como:

a tentativa de esclarecer a atitude que seria conveniente diante de questionamentos concretos como pena de morte, clonagem, homoparentalidade, justiça social, aborto, relação com o ambiente e com os animais, eutanásia e outros menos discutidos publicamente, mas também complicados, como o lançamento de anões ${ }^{(30)}$ ou o prejuízo de ter nascido ${ }^{(31)}$.

(25) Desenvolvimento diretamente inspirado em FIALAIRE J.; MONDIELLI E. Droits fondamentaux et libertés publiques, Paris: Ellipses, 2005. p. 206.

(26) PEDROT, Ph. (Dir.). Dictionnaire de droit de la santé et de la biomédecine. Paris: Ellipses, 2006. (27) V. COMITÉ CONSULTATIF NATIONAL D'ÉTHIQUE (CCNE) (France). Disponível em: <http:// www.ccne-ethique.fr/francais/start.htm>. Para uma abordagem das relações entre direito e ética, $v$. MARTINEZ, E. Les rapports entre de l'éthique et du droit à propos des lois de bioéthiques. Revue Générale de Droit Médical, n. especial, p. 114 et s., (Dix ans de lois de bioéthiques en France), 2006 (28) Cf. MONDIELLI, E. L'essentiel de la bioéthique et du droit de la biomédecine. Gualino LextensonEditions, (Coll. Les Carrés), p. 25 et s.

(29) OGIEN R., L'éthique aujourd'hui. Folio, 2007. (Coll. Essais).

(30) Em referência ao caso chamado de "lançamento de anões" tendo por objeto a célebre decisão Conseil d'Etat. 27 octobre 1995 commune de Morsang-sur-Orge Ass. 27 oct. 1995 , rec. p. 372. v. infra concernente ao princípio da diginidade da pessoa humana.

(31) Em referência à decisão chamada de "Perruche" da Corte de Cassação Francesa de 17 de novembro de 2000, que suscitou vivas controvérsias; Cass Ass. Plén. 17 nov. 2000 n. 99-13.701, C. 
Para compreender a abordagem atual ou habitual, pode-se, particularmente, se referir à definiçao dada pelo dicionário, que entende por moral "o conjunto de regras de conduta consideradas como válidas de maneira absoluta"(32). Em suma, a moral permite distinguir o bem do mal.

A ética segue uma reflexão crítica sobre situações e comportamentos. A abordagem proposta por Christian Hervé, professor de Saúde Pública da Faculdade de Medicina Necker-Enfants Malades, que dirige o doutorado de Ética Médica e Biológica da Universidade René-Descartes (Paris V), permite distinguir claramente moral de ética. Em oposição a seu paralelo latino, "moral", a ética supõe que nos interroguemos sobre os princípios e que os discutamos.

Em sua reflexão, a ética se inspira na prática. $A$ reflexão ética não seria exclusiva de uma elite. Se, na área biomédica, ela se elabora em todas as disciplinas abertas à saúde, ela resulta de confrontações e de trocas, oferecendo um exemplo de multidisciplinariedade. Seriam de pouco valor esse intercâmbio e essa dinâmica, se não estivessem submetidos a uma avaliação rigorosa. Os métodos e os resultados se validam, aqui, como em todo o campo científico. A Ética encontra, naturalmente, sua fonte de reflexão na ação. Não se espera nenhuma inflexão da prática, fora do empreendimento paralelo de informação. Fazer e saber fazer é, aqui como lá, a chave da eficácia(33).

\section{Direito médico e direito da bioética(34)}

Habitualmente, por direito médico tem-se o campo do direito que rege o exercício da medicina. De toda forma, constata-se que não há definição deste ramo do direito que seja unanimente aceita. Muitas concepções de direito médico foram desenvolvidas.

Distingue-se, em primeiro lugar, uma interpretação que se pode qualificar de clássica, encarnada, notadamente, na França por Savatier e largamente aceita ${ }^{(35)}$. Em seu tratado de direito médico, o autor entende que este ramo do direito é o estudo "das relações jurídicas que envolvem o médico". O direito médico é percebido como se interessasse, essencialmente, aos direitos e deveres do médico em relação aos seus pacientes e colegas (com esta abordagem, laços íntimos são feitos entre o direito médico e a

Labrouse et B. Mathieu, D. 2000 Point de vue, N) 44; G. Mémeteau, L'action de vie dommageable Jurisclasseur périodique éd. Générale. 2000, I, n. 279; para uma análise crítica v. M. Fabre-Magnan, Avortement et responsabilité médicale, Revue ytrimestrielle de droit civil . 2001, p. 287.

(32) Le Robert, dictionnaire historique de la langue française, Rey A. (dir. ).

(33) INSERM. Disponível em: <http://infodoc.inserm.fr/ethique/Ethique.nsf/397fe8563d75f39bc12563 f60028ec43/3b3eb52f24d1f908c125655900572465?OpenDocument>.

(34) Cf. MONDIELLI, E. op. cit., p. 29-30.

(35) SAVATIER, R. et al. Traite de droit medical. Paris: Editeur Lib. Techniques, 1956. 
deontologia médica ou a ética profissional médica). Nessa linha, Gérard Mémeteau, em sua obra Droit médica/(36), definiu o direito médico como tendo "por objeto a definição de regras de conduta para os profissionais da saúde, dentro de sua atividade profissional, e prever sanções às falhas, sob a inspiração dos princípios da moral médica que constituem uma de suas fontes".

Notam-se outras interpretações do direito médico. De fato, certos autores (Tomkin, Hanafin, Van Oosten ....) ${ }^{(37)}$ criticam a abordagem clássica por ser muito estreita e propõem a compreensão do direito médico como sendo a aplicação da Constituição, da legislação e da jurisprudência, assim como dos textos internacionais na relação médico/paciente, no contexto desta relação e a toda consequência que dela decorre necessariamente ${ }^{(38)}$. O direito médico cobriria assim a regulamentação relativa aos atos e pareceres terapêuticos e à dispensação de cuidados em geral.

Para tratar da relação "direito médico", "direito da bioética" e "direito da biomedicina", a análise desenvolvida por Romeo-Casabona e outros autores parece particularmente interessante ${ }^{(39)}$. Esses estudiosos propõem como definição de direito médico:

as partes da ordenação jurídica que concernem à Medicina, ou seja, a profissão médica e, por extensão, outras profissões da saúde ou relacionadas a ela... De toda maneira, à vista do constante alargamento do campo das atividades que impactam a saúde, o direito médico inclui, desde então, igualmente os efeitos jurídicos da aplicação, aos seres humanos, do que se chama de ciências biomédicas, a saber não apenas a medicina, como também a biologia (por exemplo, a genética), a bioquímica, a biofísica,...

Os autores utilizam a expressão "direito médico", assim como Herman Nys em seu Recueil international de législation sanitaire, de 1998, considerando que essa disciplina, juntamente com a bioética, diz respeito às ciências biomédicas e sua influência nos seres humanos, o direito médico representa o aspecto jurídico e a bioética, o aspecto ético. O prefixo "bio" acrescentaria uma dimensão existencialista à medicina. Dentro dessa abordagem, o direito médico englobaria conceitos tanto jurídicos como médicos e, por meio de áreas como a engenharia genética, os conceitos relevantes das ciências biológicas. O objeto do direito biomédico é constituído pela interação dessas ciências com a medicina e o direito.

(36) MEMETEAU, G. Cours de droit médical. Editeur Etudes Hospitalières, 2006. p. 435.

(37) NYS H., Medical law and health law: from co-exitence to symbiosis? In: INTERNATIONAL DIGEST OF HEALTH LEGISLATION, 49, p. 1-18, 1998. v. notamment p. 3-4.

(38) V. Id. Ibid.

(39) Id. Ibid., p. 6. 


\section{A BIOÉTICA ENQUANTO CIÊNCIA?}

A bioética aparece para alguns autores como uma ciência completa: a bioética seria uma ciência do direito da ciência ${ }^{(40)}$.

\section{A bioética, uma ciência do direito?}

Para esses autores, a bioética é, antes de tudo, uma ciência do direito, pois "contém regras de direito que compõem um verdadeiro ramo do direito". O que caracteriza, principalmente, a regulação do direito é seu caráter coercitivo e obrigatório. Com as primeiras leis chamadas de "bioética", de 1994, o legislador consagrou as regras internas da bioética. De fato, as leis de 1994 foram assumidas como soft law (pareceres e recomendações dos comitês de ética) e da jurisprudência. Além disso, as regras legais têm um significativo valor normativo como confirma a lei de 06 de agosto de 2004, sobre bioética (ver, por exemplo, as disposições integradas pela lei no Código Penal que são imperativas por natureza).

Os autores, anteriormente evocados, consideram que a bioética constitui um verdadeiro ramo do direito. Esta afirmação, nos parece, muito delicada para se sustentar. De fato, para que se tenha um ramo do direito, é necessário que as regras que se relacionam com as diferentes áreas tenham uma autonomia que permita formular soluções próprias, específicas. Ora, uma das características do ordenamento jurídico francês, em matéria de bioética, é sua aparente ruptura - as disposições legais se encontram dispersas em diversos códigos. Contudo, esses autores, como justificativa, relevam que a matéria se articula em torno de certos princípios gerais colocados pelo Código Civil e pelo Código Penal e que as disposições particulares de implementação destes princípios se originam, essencialmente, do Código de Saúde Pública.

\section{A bioética, um direito da ciência}

Para esses autores, a bioética é um direito da ciência no sentido que toca os aspectos da ciência relacionados com o ser humano. Porque "direito do homem", ele pratica uma proteção da espécie humana, da pessoa humana, enfim, do corpo humano.

O direito positivo francês vem confirmar essa análise. O Código Civil Francês $^{(41)}$ pôs em prática, inicialmente, a da espécie humana. De fato, seu

(40) LISANTI C.; RESPAUD J.L. La bioéthique existe-t-elle? Revue Générale de Droit Médical, n. spécial (Dix ans de lois de bioéthiques en France), p. 37 et s., 2006.

(41) Para acessar o Código Civil Francês v. v. LEGIFRANCE. Code Civil. Disponível em: <http:// www.legifrance.gouv.fr/affichCode.do?cidTexte=LEGITEXT000006070721\&dateTexte=20100508 > . 
artigo 16-4, nascido de uma lei de 1994, afirma um princípio geral de integridade da espécie humana e proibe toda prática de eugenia. Note-se, de toda maneira, que a lei de 06 de agosto de 2004, relativa à bioética, atenua o alcance deste princípio validando certas práticas atuais (por exemplo, a prática da criança chamada "medicamento", ver Art. L. 2131-4-1 do Código de Saúde Pública ${ }^{(42)}$ ). O legislador francês organizou, em paralelo, uma proteção à pessoa humana, que resulta dos princípios de dignidade e de respeito ao ser humano, desde o início da vida (Art. 16 e Art. 16-1 do Código Civil). Note-se que a lei de 06 de agosto de 2004 realizou certas adaptações em termos de proteção das características genéticas de uma pessoa (Art. 16-10 do Código Civil) e de identificação de marcadores genéticos (Art. 16-11 do Código Civil). O direito francês pratica uma proteção de partes e de produtos do corpo humano por meio da lei de 1994 que prevê a inviolabilidade do corpo humano e sua não comercialização (ver Art. 16-1 e 16-3 do Código Civil). Por fim, a lei de 06 de agosto de 2004 modifica o art. 16-3 ao 1ํ do Código Civil que afirma que "não se pode atentar contra a dignidade humana a não ser em caso de necessidade médica da pessoa ou, excepcionalmente, no interesse terapêutico de outrem".

\section{AS ESPECIFICIDADES DO DIREITO DA BIOÉTICA}

São numerosas as especifidades do direito da bioética. Construído a partir de uma certa concepção do lugar da pessoa, este direito, perseguindo os objetivos comuns de outros ramos do direito, se internacionaliza. É, igualmente, precursor e prospectivo.

- O direito da bioética é um direito que se constrói a partir de uma concepção particular do lugar da pessoa no universo e no seio da comunidade humana no passado, presente e futuro. De fato, ele se estrutura e se desenvolve em uma perspectiva de respeito e de proteção da dignidade da pessoa humana. Este princípio de dignidade, ao lado do princípio da liberdade da pessoa, aparece como "princípio matricial" da bioética, retomando uma célebre fórmula de $N$. Lenoir et $B$. Mathieu ${ }^{(43)}$.

- Em segundo lugar, o direito da bioética é um direito que persegue simultaneamente seus objetivos, partilhados com outros ramos do direito como o direito ambiental, quais sejam: controle de riscos; obrigação de proteção dos direitos das pessoas; preservação da espécie humana (doravante o progresso científico permitindo modificações genéticas).

(42) Para acessar o Código de Saúde Pública v. LEGIFRANCE. Code de la Santé Publique. Disponível em: <http://www.legifrance.gouv.fr/affichCode.do?cidTexte=LEGITEXT000006072665\&dateTexte= 20100508>.

(43) LENOIR N.; MATHIEU B. Le droit international de la bioéthique (textes). Paris: PUF, 1998. p. 16. 
- Em terceiro, o direito da bioética é um direito que se internacionaliza. Em razão dos objetivos perseguidos, os Estados se conscientizaram que, para atingir metas com uma certa eficácia, eles deveriam cooperar no plano regional e internacional. Esta é a razão pela qual, após o fim do segundo grande conflito mundial, viu-se, progressivamente, emergir e depois se afirmar um direito internacional da bioética e, paralelamente, direitos regionais da bioética e da biomedicina ${ }^{(44)}$.

- Em quarto lugar, o direito da bioética aparece como um direito "precursor", no sentido em que ele se desenvolve a partir de numerosas e variadas fontes: atos unilaterais de organizações internacionais com força de obrigação (regulamentos/diretivas comunitárias); tratados internacionais, declarações, e recomendações de organizações internacionais; declaração ou textos de ONGs, como, por exemplo, a AMM; comitês de ética internacionais, europeus ou nacionais etc.

- Por fim, o direito da bioética é um direito "prospectivo", na medida em que tenta identificar respostas aos desafios da genética dirigida ao homem (a questão emblemática da clonagem, por exemplo).

Dentro de uma discussão bioética, diversas lógicas, por vezes contraditórias, entram em conflito(45). Esta situação tem, por consequência, tornado difícil a criação de normas aceitáveis e aceitas. De maneira simplificada, distinguem-se duas categorias de lógicas que, embora contraditórias, devem ser conciliadas. Uma primeira categoria (que pode-se chamar de "lógica A") impulsiona o desbravamento de novas etapas no campo do conhecimento e da economia. Trata-se, na prática, de uma lógica da pesquisa e do desenvolvimento, de um lado, e da valorização econômica, de outro. A segunda categoria de lógica ("lógica B") remete a reflexões que buscam temperar a "lógica A". Na prática, são aquelas de proteção dos direitos do homem e das liberdades fundamentais, de um lado, e da proteção ambiental, do outro. Traduções de interesses divergentes, estas lógicas, quando em operação, tornam muito difícil a criação de normas aceitáveis e aceitas. O direito pode ser um instrumento de elaboração destas normas.

Em razão do caráter extremamente rápido dos avanços científicos e médicos, o direito deve acompanhar esse progresso. Assim, ele não pode ser, simplesmente, "um seguidor". Sua tarefa torna-se, por consequência, terrivelmente difícil, a saber: conciliar o inconciliável. No campo biomédico, a regulação jurídica de pesquisas e técnicas tem sido contestada há muito tempo. O direito concorre, às vezes, com outros sistemas normativos

(44) Para perceber esta dimensão, ver Ch. BYK (dir.), Bioéthique et droit international. Autour de la Déclaration universelle sur la bioéthique et les droits de l'homme, Paris: Litec 2007; v. igualmente LENOIR N.; MATHIEU B. Le droit international de la bioéthique (textes), cit., e LENOIR N.; MATHIEU B. Les normes internationales de la bioéthique, cit; para uma compreensão sintética v. MONDIELLI, E. op. cit., p. 39-62.

(45) MONDIELLI, E. op. cit., p.34-35. 
originários das comunidades científica e médica. Certos profissionais são mesmos reticentes em relação a legislações muito específicas e completas. Até hoje, a maioria dos atores destas comunidades estão de acordo com a necessidade de se fixar regras e exigências comuns. Por seu lado, o grande público, em sua maioria, demanda uma delimitação jurídica dos avanços científicos e médicos. A tendência atual se caracteriza por uma presença cada vez mais importante do direito no campo biomédico.

\section{O PRINCÍPIO DA SALVAGUARDA DA DIGNIDADE DA PESSOA HUMANA, PRINCÍPIO MATRICIAL DA BIOÉTICA E DO DIREITO DA BIOMEDICINA}

Fundamento da proteção internacional dos direitos fundamentais e, mais particularmente, de toda reflexão sobre bioética e biomedicina, o princípio da dignidade, qualificado de princípio matricial, é difícil de identificar e definir. A despeito desta dificuldade, o direito francês e o europeu têm afirmado o caráter indisponível da dignidade da pessoa humana.

\section{O princípio da dignidade, fundamento da reflexão bioética e do "biodireito"}

Toda a reflexão bioética em termos de "biodireito" (bio-law) está fundada sobre o princípio da dignidade. Na França, o princípio da salvaguarda da vida humana foi constitucionalizado pela jurisprudência do Conselho Constitucional (CC., n. 94-343 DC 27 juillet 1994, Lois "Bioéthiques")(46). De fato, nessa decisão, o juiz constitucional baseou esse princípio no Preâmbulo da Constituição de 1946, alínea 1a., segundo o qual:

(...) em consequência da vitória alcançada pelos povos livres sobre os regimes que tentaram escravizar e degradar a pessoa humana, o povo francês proclama novamente que todo ser humano, sem distinção de raça, religião, crença, conta com direitos inalienáveis e sagrados. Ele reafirma solenemente os direitos e liberdades do homem e do cidadão consagrados pela Declaração de Direitos de 1789 e os princípios fundamentais reconhecidos pelas leis da República.

Para o Conselho Constitucional, infere-se desta alínea do Preâmbulo que "a salvaguarda da dignidade da pessoa humana contra toda forma de

(46) Para acessar as decisões do Conselho Constitucional v. CONSEIL CONSTITUTIONNEL. Disponível em: <http://www.conseil-constitutionnel.fr/>; pour accéder à la décision v. CONSEIL CONSTITUTIONNEL. Décision n 94-343/344 DC du 27 juillet 1994. Disponível em: <http://www.conseilconstitutionnel.fr/conseil-constitutionnel/francais/les-decisions/acces-par-date/decisions-depuis1959/1994/94-343/344-dc/decision-n-94-343-344-dc-du-27-juillet-1994.10566.html>. 
escravidão e degradação é um princípio de valor constitucional”. O princípio da salvaguarda da pessoa humana é geralmente analisado pela doutrina como sendo um princípio matricial (Lenoir/Mathieu) ${ }^{(47)}$ do qual decorrem, entre outras, construções jurídicas criadas para proteger o corpo humano e, de uma maneira mais geral, para proteger e garantir a primazia da pessoa face às ciências da vida e a suas implicações.

Definir a dignidade humana é uma empreitada especialmente difícil e delicada, para não dizer perigosa. O conceito, qualificado frequentemente de fluído, é normalmente utilizado para apoiar reivindicações contraditórias. O exemplo do debate sobre a legislação da eutanásia é uma ilustração perfeita: aqueles que são favoráveis à legalização sobre certas condições destacam o "direito de morrer dignamente" e aqueles que são contrários a toda legalização se apóiam sobre o princípio da dignidade da pessoa. A noção de dignidade humana engloba, finalmente, conceitos muito diferentes: exigência do consentimento dos pacientes ao tratamento, interdição de práticas discriminatórias em relação aos pacientes, princípio da não comercialização do corpo humano etc.

O conceito de dignidade deve, imperativamente, ser distinguido daquele que trata da autonomia, se bem que existam laços estreitos entre eles. $O$ respeito à autonomia do indivíduo é uma das facetas ou expressões do respeito à dignidade da pessoa, no sentido em que o respeito a sua autonomia é imposto pelo respeito a sua dignidade. Mas, ao mesmo tempo, deve-se respeitar a dignidade das pessoas que não podem ser autonômas (por exemplo, os recém-nascidos ou doentes mentais). No plano internacional, a dignidade da pessoa humana constitui o fundamento da proteção dos direitos fundamentais afirmada nos grandes textos internacionais e regionais (Declaração Universal dos Direitos do Homem, de 1948; Pacto das Nações Unidas relativo aos Direitos Civis e Políticos; Declaração Universal sobre o Genoma Humano, chamado de "patrimônio da humanidade"; Declaração Universal sobre a Bioética e os Direitos dos Homens; Convenção de Oviedo etc.). O princípio da dignidade se exprime pelo reconhecimento da liberdade da pessoa.

No direito francês, ao lado das disposições do Código Penal, (Capítulo V do Código Penal, "Violações à dignidade da pessoa"(48)), a dignidade é assegurada por diferentes textos, notadamente, o artigo 16 do Código Civil, seção 2 da lei de 29 de julho de 1994: "A lei assegura a primazia da pessoa, proibindo todo tipo de violação a sua dignidade e garantindo o respeito ao ser humano desde o início da vida"; ou o artigo L. 1110-2 do Código da Saúde Pública (CSP) "a pessoa doente tem o direito ao respeito a sua dignidade".

(47) Op. cit.

(48) Para acessar ao texto do Código Penal Francês v. LEGIFRANCE. Code Pénal. Disponível em: $<$ http://www.legifrance.gouv.fr/affichCode.do?cidTexte=LEGITEXT000006070719\&dateTexte $=2010$ 0508>. 


\section{A indisponibilidade da dignidade}

A indisponibilidade da dignidade é assegurada por parte da doutrina, na medida em que ela não é comercializável. Não se pode renunciar à dignidade porque um indivíduo não pode se excluir da humanidade. Esta indisponibilidade é consagrada pelo direito francês (ver, por exemplo, para as juridições administrativas, CE., de 27 de outubro de 1995, commune de Morsang-sur-Orge ${ }^{(49)}$; para as juridições judiciais, CA. Paris, 28 de maio de 1996, $X$ et autres $c /$ Sté Benetton ${ }^{(50)}$ ) e pelo o direito europeu (ver, por exemplo, Cour EDH 22 nov. 1995, C. R. c/ Royaume-Uni(51)).

A título de precisão, particularmente para os leitores não juristas, e a título ilustrativo, recordamos que o Conselho de Estado Francês, na célebre decisão commune de Morsang-sur-Orge (caso conhecido como "lançamento de anões") reconheceu a legalidade das decisões que proibem este tipo de espetáculo.

Considerando que cabe à autoridade investida do poder de polícia municipal tomar todas as medidas para prevenir uma violação à ordem pública; que o respeito da dignidade da pessoa humana é um dos componentes da ordem pública; que a autoridade investida do poder de polícia municipal pode, mesmo na falta de circunstâncias locais particulares, proibir uma atração que viole o respeito à dignidade da pessoa humana;

O juiz administrativo esclarece em seguida que:

A atração "lançamento de anões", que consiste em lançar um anão pelos espectadores, utiliza como projétil uma pessoa com deficiência física, apresentada como tal; pelo seu próprio objeto, tal atração atenta contra a dignidade da pessoa humana.

A diginidade da pessoa é, de fato, analisada como um dos componentes da ordem pública. Esta jurisprudência aparece fundamentalmente porque é importante lembrar que, no caso acima descrito, o anão afirmava que seu trabalho (o fato de participar volutariamente do espetáculo em troca de remuneração) constituía para ele um meio de inserção na vida profissional e invocava os princípios da liberdade de trabalho e da liberdade comercial e industrial. O Conselho de Estado não seguiu este tipo de argumento e considerou que esta atividade atentava contra a dignidade da pessoa, pouco importando que $\mathrm{o}$ anão se prestasse livremente à exibição. $\mathrm{O}$ juiz administrativo fundamentou-se na ideia de humanidade e não de liberdade.

(49) V. supra nota 30; para acessar a jurisprudência do Conselho de Estado v. . CONSEIL D'ETA. Disponível em: <http://www.conseil-etat.fr/cde/>.

(50) Cour d'Appel de Paris, 28 mai 1996, Dalloz 1996, p. 617, note B. EDELMAN

(51) Para acessar as decisões da Corte Europeia dos Direitos dos Homens v. COUR EUROPÉENNE DES DROITS DE L'HOMME. Disponível em: <http://www.echr.coe.int/echr/>. 


\section{CONSIDERAÇÕES FINAIS}

Ao final desta contribuição, que não tinha outra ambição a não ser esclarecer o conceito de bioética comparando-o às demais ideias que, com ele, mantêm laços estreitos, destacaremos que a questão da bioética torna-se cada vez mais central no debate público, tanto são importantes os desafios sociais, individuais e econômicos. A evolução e o avanço extraordinário das ciências da vida, com as novas perspectivas que elas abrem, desestabilizaram esquemas tradicionais de pensamento. O homem, graças a esse progresso, dispõe de meios que lhe permitem perceber os segredos da vida. A compreensão da linguagem genética abre possibilidades inimagináveis e torna possível "corrigir" certos erros da natureza como mostra, por exemplo, o potencial das terapias genéticas. Mas, o progresso científico e médico vem contribuindo para a exarcebação de uma série de questões que têm por objeto o corpo humano e que têm estado no centro da reflexão ética e jurídica: o corpo da pessoa deve ser compreendido como o prolongamento da pessoa ou trata-se de uma coisa?

O avanço da biologia e das ciências da vida, ao abrir novas perspectivas de intervenção sobre o corpo humano, nos convida a repensar nossa relação com o "ser vivo", com o corpo e a doença, com a reprodução, a paternidade e com a filiação. Esse avanço nos conduz a nos perguntar sobre nossa responsabilidade com as gerações futuras. Neste furacão, nossas sociedades têm sentido a necessidade de fixar balizas de ordem ética. Por esta razão, por exemplo, a França foi um dos primeiros países a contar com um Comitê Consultivo Nacional para as Ciências da Vida e da Saúde que tem por missão esclarecer as autoridades públicas sobre as implicações éticas da evolução técnica e científica no campo da biologia e da medicina. Porém, o progresso, ao confundir nossos esquemas tradicionais em relação à vida, é fonte de discussão permanente. A consequência desta situação é que não existe consenso sobre uma crença ou uma ética em nossos países. Esta falta de consenso constitui um obstáculo à elaboração de uma teoria jurídica do direito à vida que possa ser aceita pela maioria dos cidadãos.

\section{REFERÊNCIAS BIBLIOGRÁFICAS}

AZOUX-BACRIE L. (Dir.), Bioéthique, bioéthiques. Bruxelles, Nemessis, Bruylant, 2003.

BAUZON S. La personne biojuridique. Paris: PUF, Paris, 2006. (Coll. Quadrige).

BINET, R-J. Le nouveau droit de la bioéthique. Lexis Nexis LITEC, 2005. (coll. Carré droit). 
CODE de déontologie médicale (Poche). Introduit et commenté par René (Ed.) Louis, préface de Paul Ricœur. Seuil, 1996. 205 p. (Coll. Points Essais). COMITÉ CONSULTATIF NATIONAL D’ÉTHIQUE (CCNE) (France). Disponível em: <http://www.ccne-ethique.fr/francais/start.htm>.

COMITÉ NATIONAL CONSULTATIF D'ÉTHIQUE POUR LES SCIENCES DE LA VIE ET DE LA SANTÉ. Disponível em: <http://www.ccne-ethique.fr/>.

CONSEIL CONSTITUTIONNEL. Décision n 94-343/344 DC du 27 juillet 1994. Disponível em: <http://www.conseil-constitutionnel.fr/conseil-constitutionnel/ francais/les-decisions/acces-par-date/decisions-depuis-1959/1994/94-343/ 344-dc/decision-n-94-343-344-dc-du-27-juillet-1994.10566.html>.

. Disponível em: <http://www.conseil-constitutionnel.fr/>.

Décision n. 74-54 du 15 janvier 1975, Loi relative à l'interruption

volontaire de la grossesse. Disponível em: <http://www.conseilconstitutionnel.fr/decision/1974/7454dc.htm>.

CONSEIL D’ETA. Disponível em: <http://www.conseil-etat.fr/cde/>.

CONVENTION «BIOMÉDECINE» DU CONSEIL DE L’EUROPE. Disponível em: <http://conventions.coe.int/Treaty/fr/Treaties/Html/164.htm>.

COUR EUROPÉENNE DES DROITS DE L'HOMME. Disponível em: <http:// www.echr.coe.int/echr/>.

DOSSIER Législatif de l'Assemblée Nationale. Disponível em: <http:// www.assemblee-nationale.fr/12/dossiers/bioethique.aspv>; <http:// www.assemblee-nationale.fr/13/dossiers/eval_bioethique.asp >; <http:// www.assemblee-nationale.fr/13/rap-off/i1325-tl.asp >.

DOSSIER législatif du Sénat. Disponível em: <http://www.senat.fr/dossierleg/ pjl01-189.html>.

DOSSIER Législatif sur Legifrance. Disponível em: <http://www.legifrance. gouv.fr/>;<http://www.legifrance.gouv.fr/affichLoiPubliee.do;jsessionid=412A 138D95732EC4945445F372DF2A1A.tpdjo09v_1?idDocument=JORFDOLE000 017759387\&type=general>.

DURAND, G. Introduction générale à la bioéthique. FIDES/Cerf, 1999. 565 p.

FEUILLET-LE MINTIER B. (Dir.). Normativité et biomédecine. Paris: Economica, 2003. (Coll. Etudes juridiques).

FIALAIRE J.; MONDIELLI E. Droits fondamentaux et libertés publiques, Paris: Ellipses, 2005.

HOTTOIS, G. Qu'est-ce que la bioéthique? Paris: Vrin, 2004.

INSERM. Disponível em: <http://infodoc.inserm.fr/ethique/Ethique.nsf/397fe8 $563 d 75 f 39 b c 12563 f 60028$ ec43/3b3eb52f24d1f908c125655900572465? OpenDocument>. 
J. ROY D., WILLIAMS J. R, M. DICKENS; BAUDOUIN J-L. La bioéthique: ses fondements et ses controverses. Montréal: Editions du Renouveau Pédagogique, 1995.

LA DOCUMENTATION FRANCAISE. Sur la révision des lois de bioéthique en 2010 v. /Dossier d'actualité - La Documentation française: <http:// www.ladocumentationfrancaise.fr/dossier_actualite/bioethique/ind(...)>.

LEGIFRANCE. Code Civil. Disponível em: <http://www.legifrance.gouv.fr/ affichCode.do?cidTexte=LEGITEXT000006070721\&dateTexte=20100508 > .

Code Pénal. Disponível em: <http://www.legifrance.gouv.fr/ affichCode.do?cidTexte=LEGITEXT000006070719\&dateTexte=20100508>.

Code de la Santé Publique. Disponível em: <http://www.legifrance. gouv. fr/affichCode.do?cidTexte=LEGITEXT000006072665\&dateTexte $=2010$ 0508>.

LENOIR N.; MATHIEU B. Le droit international de la bioéthique (textes). Paris: PUF, 1998.

Les normes internationales de la bioéthique. Paris:

PUF, 1998. (Que-sais-je?, n. 3356).

LISANTI C.; RESPAUD J.L. La bioéthique existe-t-elle? Revue Générale de Droit Médical, n. spécial (Dix ans de lois de bioéthiques en France), 2006.

MARTINEZ, E. Les rapports entre de l'éthique et du droit à propos des lois de bioéthiques. Revue Générale de Droit Médical, n. especial, (Dix ans de lois de bioéthiques en France), 2006.

MEMETEAU, G. Cours de droit médical. Editeur Etudes Hospitalières, 2006.

MONDIELLI, E. L'essentiel de la bioéthique et du droit de la biomédecine. Gualino LextensonEditions, (Coll. Les Carrés).

NYS H., Medical law and health law: from co-exitence to symbiosis? In: INTERNATIONAL DIGEST OF HEALTH LEGISLATION, 49, p. 1-18, 1998.

OGIEN R., L'éthique aujourd'hui. Folio, 2007. (Coll. Essais).

PEDROT, Ph. (Dir.). Dictionnaire de droit de la santé et de la biomédecine. Paris: Ellipses, 2006.

SAVATIER, R. et al. Traite de droit medical. Paris: Editeur Lib. Techniques, 1956.

VAN RENSSELAER POTTER. Bioethics: bridge to the future, Englewoods Cliffs. New Jersey: Prentice-Hall, 1971. 205 p.

Bioethics, the science of survival. Perspectives in Biology and Medecine, n. 14, p. 127-153, 1970.

WORLD MEDICAL ASSOCIATION. Disponível em: <http://www.wma.net/en/ 10home/index.html>. 